\title{
Introduction: the interface of morphology and phonology
}

\author{
Dany Amiot • Cédric Patin • Natalia Grabar • \\ Fayssal Tayalati · Delphine Tribout
}

Received: 25 November 2014 / Accepted: 25 November 2014 / Published online: 10 December 2014

(C) Springer Science+Business Media Dordrecht 2014

In September 2013 the conference "Morphology and its Interfaces" was held at the University of Lille 3 . The conference addressed questions concerning morphology and its internal or external interfaces, from a diachronic or synchronic perspective. Its aim was to foster the study of interactions between morphology and other domains of linguistics. This special issue is devoted to the phonology-morphology interface, and presents five selected papers on this topic.

There is little doubt that the relation between phonology and morphology is of great importance for the analysis of various phenomena. Several flectional and derivational phenomena directly involve both domains, for example reduplication and stem alternation. Other morphological phenomena need to have recourse to phonological constraints to be explained. Booij (2000) lists different sorts of interactions between word formation and phonology, such as the influence of morphological structure on the phonetic shape of complex words, and the role of phonological output conditions in making a choice between competing affixes.

However, different from other types of interface such as the syntax-phonology interface (see Elordieta 2008 and Selkirk 2012, for overviews), the phonologymorphology interface received little attention from scholars these last decades, with notable exceptions such as Booij (2000, 2002, 2005, Chap. 7), McCarthy (1981, 1983), Inkelas and Zoll (2005), Inkelas (2011, 2014), Plénat (1996), Roché and Plénat (2003), Lignon and Plénat (2009) among others. Several factors may explain this situation.

D. Amiot $(\varangle) \cdot$ C. Patin · N. Grabar · F. Tayalati · D. Tribout

Département des Sciences du Langage, Université de Lille 3, Bât. B4, Rue du Barreau, BP 60149, 59653 Villeneuve d'Ascq Cedex, France

e-mail: dany.amiot@univ-lille3.fr 
First, the traditional ${ }^{1}$ Optimality Theory (henceforth OT-Prince and Smolensky 1993/2004; McCarthy and Prince 1993), that was dominant in phonology for twenty years, assumes the parallel application of both morphological and phonological constraints, and thus tends to blur the morphology-phonology distinction (Nishiyama 1999). Generalized Alignment constraints (McCarthy and Prince 1993), for instance, align morphemes with categories that may be morphological (e.g. the stem in Taga$\log$ ) or phonological (e.g. the foot in Ulwa) in nature. On the one hand, this perspective led to substantial improvements in our understanding of various morphophonological processes, such as reduplication or truncation-see Downing (2006) for an overview. On the other hand, with phonologists and morphologists working together on the same problems using a common theoretical framework, the need to examine the interface between phonology and morphology has become weaker, and the boundaries of these two components of the grammar have thus become fuzzy. As a consequence, some OT scholars such as Green $(2003,2004,2005)$ advocate a strict separation of phonology and morphology, leading to the development of morphemespecific constraints or rankings (see Pater 2006 for an overview). Since in OT phonological processes are reduced to the interaction between faithfulness and markedness constraints, alternation rules in which markedness principles appear to play no role have to be considered purely morphological in nature. To illustrate this difference between phonological and morphological rules, Green (2003) discusses two consonant mutation rules in Manx. One of the rules, a classical lenition process that he calls Phonological Lenition, optionally turns the voiceless stops to voiced stops or fricatives of the same place of articulation, and voiceless fricatives to voiced fricatives of the same place of articulation, in intervocalic position. Since the lenition of stops in intervocalic position is cross-linguistically well attested, and since the process affects natural classes in a uniform way, Green claims the rule to be purely phonological, as opposed to another mutation rule, which he calls Morphosyntactically triggered Lenition. The latter rule is restricted to specific environments (e.g. nouns after possessives or numerals), and involves 'unnatural' changes such as $/ \mathrm{d} / \rightarrow[\mathrm{\gamma}]$.

The research on the phonology-morphology interface has also been weakened by the emergence of models that consider one of the subfields to be radically different in nature from what is traditionally assumed. In the Distributed Morphology framework (henceforth DM-Halle and Marantz 1993, 1994 and subsequent literature), morphemes are in fact syntactic terminal nodes. This model rejects the Lexicalist hypothesis, and as a consequence the existence of lexical items (Harley and Noyer 1999), reducing most of the properties that traditionally belong to morphology to the interface between phonology and syntax. Since DM assumes "that the determination of government relations in word structures [...] follows the same principles as for government relations in the syntax" (Halle and Marantz 1993: 146), and thus that there is no division between morphology and syntax, it excludes the existence of phonology-morphology interface phenomena that may be of different type from phonology-syntax interface phenomena. On the other hand, the idea of phonology as an independent component of the grammar has been questioned in other studies: some scholars consider the distinction between phonetics and phonology to be

\footnotetext{
${ }^{1}$ This is not true for later OT models such as Stratal OT (Kiparsky 2003 and subsequent literature).
} 
irrelevant (e.g. Ohala 1990; Flemming $2001^{2}$ ), while others "relat[e] lexical representations of morpheme sequences directly to their surface/phonetic forms, without intermediate derivational stages" (Harms 1995). Most notably, several studies have advocated a direct morphological conditioning of phonetic implementation, without the mediation of phonology (e.g. Cho 2001; Ernestus and Baayen 2006; Sproat and Fujimura 1993-see Kawahara 2011 for an overview, and BermúdezOtero 2010 for a criticism).

The latter studies have been conducted within the Laboratory Phonology framework (Pierrehumbert et al. 2000; Cohn et al. 2012), a methodological approach where phonological analyses build upon careful experimental studies, and involve other disciplines such as cognitive or computer science. This methodological revolution also explains the relative lack of studies dedicated to the phonology-morphology Interface.

In Autonomous Morphology (Aronoff 1994 or even 'semi-autonomous morphology'-Maiden 2011, and its variants, for example, Lexical Morphology-Kiparsky 1982; rule-based realizational approaches-Anderson 1992; Stump 2001; Optimal Construction Morphology_-Inkelas and Caballero 2013), a separate component for morphology has been conceptualized, that allows to account for the specific properties of the morphological facts. The assumption of such a component necessarily raises the question of the relation between this component and the other ones. Is the morphological component completely independent from the others? If not, what are the respective roles of each component in morphological phenomena, and what is the nature of the relationship(s)?

All the papers in this special issue address in one way or another the role of phonology in the analysis of morphological processes.

Three of the papers deal with the question of the respective roles of morphology $v s$ phonology in morphological processes: the papers by Esher, Koehl and Lignon, and Labrune. Both Esher and Labrune try to determine, in two different ways, the respective roles of phonology vs morphology in the facts that they study.

Esher's paper, "Autonomous morphology and extramorphological coherence" which fits into the theoretical framework of autonomous morphology (Aronoff 1994), follows previous studies such as Maiden (2011) and Cruschina et al. (2013). The objective of Esher is to provide a more nuanced understanding of autonomous morphology and its interactions with other components of grammar. The analysis deals with paradigms in inflectional morphology, and is based on the concepts of morphome (i.e. a pure form without any semantic or morphosyntactic content, Aronoff 1994) and metamorphome ("recurrent paradigmatic stem distributions", cf. Round, forthcoming), and on the notion of hierarchy of functional coherence, put forward by Smith (2013), i.e. a ranking of morphomes according to the degree to which they correspond to extramorphological criteria. The author studies Romance verb morphology and relies on examples of metamorphomes studied by Maiden (2011). The relevant

\footnotetext{
${ }^{2}$ Note that these authors do not reject the existence of phonology. Ohala, argues that "between phonetics and phonology, phonology is the superordinate discipline" (Ohala 1990: 168). However, their refusal of any separation between phonetics and phonology has consequences for the study of the phonology-morphology interface.
} 
paradigms provide significant mismatches between the distribution of morphological forms and the distribution of syntactic, semantic or phonological functions. Such mismatches allow the author to demonstrate the existence of continuums between purely morphological phenomena, considered arbitrary, and morphological phenomena that are to some extent correlated with extramorphological features (i.e. with syntax, semantics or phonology). The author outlines a possible approach to quantifying the different sorts of coherence, and questions the relation between extramorphological motivation and diachronic resilience. She hypothesizes that phonological features have a greater importance than morphosemantic features in the diachronic resilience of metamorphomes.

Labrune's paper, "Featural linking elements in Basque compounds" deals with the phonological alternations resulting from the insertion of an element that links the components of compounds in Basque. The author proposes a unified analysis of the linking element: it is a featural morphological marker, whose underlying representation is [-voice, -continuant], and whose realization is always predictable. Moreover, she shows that featural linking elements are not a unique property of Basque but are cross-linguistically well-attested, for instance in Japanese and Korean. Even though some of these alternations can be related to general principles of the phonology of the Basque language, most of them cannot result from such principles. As a consequence, these alternations are not phonological but are (at least partially) morphologicallydriven. The structure of the compound (subordinate vs coordinate) determines the presence of the linking element. Moreover, this morphological process is also constrained by phonetic, etymological and lexical factors.

Just like Esher and Labrune, Koehl and Lignon try to highlight the respective roles of morphology and phonology. However, they argue that phonology plays no role in the competition between -ité and -itude suffixes in French. In French several suffixation processes form deadjectival nouns. Among these, -ité and -itude are very close to each other (in term of historical development, form, and meaning of the derived nouns). The authors presuppose that to avoid synonymy, two markers with the same semantico-categorial properties should not both remain active. This was true until recently: -itude suffixation was nearly unproductive (only a few nouns were coined since the 16th century), while -ité suffixation was productive. However, online data show that neologisms with -itude are now frequent. This raises the question of the factors that triggered such a revival of the suffixation in -itude: are they of phonological, semantic or morphological nature? Koehl and Lignon show that this revival is due to morphopragmatic factors, linked to the emergence of new models initiated by leader-words (négritude, bravitude). Semantically, these new models create attitude nouns; morphonologically, the neologisms with -itude are differentiated from -iténouns in several ways such as the size of the stems and the size of the derived nouns, the absence of truncation process, and the absence of sensibility to dissimilation.

In the papers by Cohen ("Probabilistic reduction and probabilistic enhancement: Contextual and paradigmatic effects on morpheme pronunciation") and Shaw et al. ("Surviving truncation: informativity at the interface of morphology and phonology"), phonology is of marginal importance, while other (more) important parameters (e.g. informativity) have an impact on it.

In her paper, Cohen explores the effects of both contextual and paradigmatic probability on the pronunciation of the subject-verb agreement in English (present singu- 
lar third person $s$ ). To measure contextual probability, she conducts an experiment that tests the number agreement attraction (more or less semantic agreement, cf. Corbett 2006). The most important parameter concerns the structure of the subject, whose conception favours variation in the realization of number agreement. Its head noun is expanded by a PP, and the head noun and the local noun (the noun inside the PP) covary in numerosity: singular, plural, collective or distributive. To calculate paradigmatic probability the author uses two distinct measures: the relative frequency, i.e. the ratio of the frequency of the two forms (with and without $s$ ) and the inflectional entropy, calculated over the entire verbal paradigm. The results show that the pronunciation of the singular $s$ suffix in English verbs is sensitive to different types of probabilities. As for contextual probability, the effect is confined to the verb stem (not to the suffix). Paradigmatic probability, on the other hand, is insensitive to entropy (contra Baayen et al. 2008), but its effect, which appears both on the suffix and the verb stem, is carried by the relative frequency of the singular form to the plural form of the verb. In this probabilistic approach, phonology plays no role: the calculations of contextual probability are at the interface of morphosyntax and semantics, and have consequences on the phonetic implementation, while those of paradigmatic probability stay inside the frame of morphology.

Shaw et al. show that information theory (cf. the seminal paper of Shannon 1948) allows to predict the syllable that will be truncated in the formation of new disyllabic NN compounds in Chinese. This paper concerns disyllabic NN compounds that are built themselves from two disyllabic Ns (e.g. xiàdi $\bar{e}+$ fúdù $\rightarrow$ diēfú, where $2+2=4 \rightarrow 2$ ). Though all logically possible truncation patterns are attested in this kind of compounds, the authors assume, contra Ceccagno and Basciano (2007), that the degree of informativity of both components of the NN compounds predicts which syllable of each component is truncated in order to obtain a disyllabic NN compound as an output. This analysis is in line with recent studies of the influence of informativity on different aspects of phonological system (stress, accent, duration, quality of epenthetic vowels, etc.). Hence, the basic hypothesis of the paper is that the "syllables that survive truncation are those that contain the most information about the expanded disyllabic form". For this purpose, they use a probabilistic model of word formation. Two indices of predictability (calculated for the left and right members of a compound) are used: the family constituent size (the number of disyllabic words that share the same right or left member) and the frequency ratio (the frequency of a compound relative to the frequency of its members). The basic hypothesis is confirmed by the statistics: syllables that get truncated are indeed the most informative ones. However, the analysis shows that the effect size of the indices vary according to the sort of compound that is at stake: pseudo-compounds (monomorphemic Chinese words written with two sino-graphs) or synthetic compounds ("real" compounds). Family size predicts truncation in pseudo-compounds, while frequency ratio predicts truncations in synthetic compounds. Such results suggest that it is not informativity itself that triggers truncation in neological Chinese disyllabic compounds.

\section{References}

Anderson, S. R. (1992). A-morphous morphology. Cambridge: Cambridge University Press. 
Aronoff, M. (1994). Morphology by itself. Cambridge: MIT Press.

Baayen, R. H., Levelt, W. M. J., Schreuder, R., \& Ernestus, M. (2008). Paradigmatic structure in speech production. Chicago Linguistics Society, 43, 1-29.

Bermúdez-Otero, R. (2010). Morphologically conditioned phonetics? Not proven. Handout from a talk at On linguistic interfaces II, Belfast, December 2, 2010.

Booij, G. (2000). The phonology-morphology interface. In L. Cheng \& R. Sybesma (Eds.), The first Glot international state-of-the-article book (pp. 287-307). Berlin: de Gruyter.

Booij, G. (2002). Prosodic constraints on stacking up affixes. In G. Booij \& J. van Marle (Eds.), Yearbook of morphology 2001 (pp. 183-202). Dordrecht: Kluwer.

Booij, G. (2005). The grammar of words. An introduction to linguistic morphology. Oxford: Oxford University Press.

Ceccagno, A., \& Basciano, B. (2007). Compound headedness in Chinese: an analysis of neologisms. Morphology, 17(2), 207-231.

Cho, T. (2001). Effects of morpheme boundaries on intergestural timing: evidence from Korean. Phonetica, $58,129-162$.

Cohn, A. C., Fougeron, C., \& Huffman, M. K. (Eds.) (2012). The Oxford handbook of Laboratory Phonology. Oxford: Oxford University Press.

Corbett, G. G. (2006). Agreement. Cambridge: Cambridge University Press.

Cruschina, S., Maiden, M. \& Smith, J. C. (Eds.) (2013). The boundaries of pure morphology. Oxford: Oxford University Press.

Downing, L. J. (2006). Canonical forms in prosodic morphology. Oxford: Oxford University Press.

Elordieta, G. (2008). An overview of theories of the syntax-phonology interface. Journal of Basque Linguistics and Philology, 42, 209-286.

Ernestus, M., \& Baayen, R. H. (2006). The functionality of incomplete neutralization in Dutch: the case of past-tense formation. In L. Goldstein, D. H. Whalen, \& C. T. Best (Eds.), Laboratory phonology 8 (Phonology and phonetics 4-2) (pp. 27-49). Berlin: de Gruyter.

Flemming, E. (2001). Scalar and categorical phenomena in a unified model of phonetics and phonology. Phonology, 18, 7-44.

Green, A. D. (2003). The independence of phonology and morphology: the Celtic mutations. ZAS Papers in Linguistics, 32, 47-86.

Green, A. D. (2004). Opacity in Tiberian Hebrew: morphology, not phonology. ZAS Papers in Linguistics, 37, 37-70.

Green, A. D. (2005). Phonology limited. Ms, Centre for General Linguistics, Typology and Universals Research (ZAS), Berlin.

Halle, M., \& Marantz, A. (1993). Distributed morphology and the pieces of inflection. In K. Hale \& S. J. Keyser (Eds.), The view from building 20 (pp. 111-176). Cambridge: MIT Press.

Halle, M., \& Marantz, A. (1994). Some key features of distributed morphology. In Papers on phonology and morphology. MIT working papers in linguistics 21 (pp. 275-288). Cambridge: MIT Press.

Harley, H., \& Noyer, R. (1999). State-of-the-article: distributed morphology. Glot International, 4, 3-9.

Harms, R. T. (1995). Two-level morphology as phonology: parallel automata, simultaneous rule application, and the elsewhere condition. Ms, University of Texas at Austin. http://www.utexas.edu/depts/ linguistics/2lev-int.pdf.

Inkelas, S. (2011). The phonology-morphology interaction. In J. Goldsmith, J. Riggle, \& A. Yu (Eds.), Handbook of phonological theory (2nd ed., pp. 68-102). Oxford: Wiley/Blackwell.

Inkelas, S. (2014). The interplay of morphology and phonology. Oxford: Oxford University Press.

Inkelas, S., \& Zoll, C. (2005). Reduplication: doubling in morphology. Cambridge: Cambridge University Press.

Inkelas, S., \& Caballero, G. (2013). Word construction: tracing an optimal path through the lexicon. New theoretical tools in the modeling of morphological exponence. Morphology, 23, 103-143.

Kawahara, S. (2011). Experimental approaches in theoretical phonology. In M. van Oostendorp, C. J. Ewen, E. V. Hume, \& K. Rice (Eds.), The Blackwell companion to phonology (pp. 2283-2303). Oxford: Wiley/Blackwell.

Kiparsky, P. (1982). Word-formation and the Lexicon. In F. Ingemann (Ed.), Proceedings of the midAmerica linguistics conference, Lawrence, Kansas, 1982.

Kiparsky, P. (2003). Finnish noun inflectio. In D. Nelson, \& S. Manninen (Eds.), Generative approaches to Finnic and Saami linguistics. Stanford: CSLI.

Lignon, S., \& Plénat, M. (2009). Echangisme suffixal et contraintes phonologiques. In B. Fradin, F. Kerleroux, \& M. Plénat (Eds.), Aperçus de morphologie du français (pp. 65-81). Paris: Presses Universitaires de Vincennes. 
Maiden, M. (2011). Morphological persistence. In M. Maiden, J. C. Smith, \& A. Ledgeway (Eds.), The Cambridge history of the Romance languages. Structures (Vol. I, pp. 155-215). Cambridge: Cambridge University Press.

McCarthy, J. (1981). A prosodic theory of nonconcatenative morphology. Linguistic Inquiry, 12, 373-418.

McCarthy, J. (1983). Phonological features and morphological structure. In J. Richardson, M. Marks, \& A. Chukerman (Eds.), Papers from the parasession on the interplay of phonology, morphology, and syntax (pp. 135-161). Chicago: Chicago Linguistic Society.

McCarthy, J., \& Prince, A. (1993). Generalized alignment. In G. Booij \& J. van Marle (Eds.), Yearbook of morphology 1993 (pp. 79-153). Dordrecht: Kluwer.

Nishiyama, K. (1999). The morphology-phonology distinction and derivational/representational view of grammar: a case of phonologically conditioned allomorphy. Explorations in English linguistics.

Ohala, J. (1990). There is no interface between phonetics and phonology. Journal of Phonetics, 18, 153171.

Pater, J. (2006). The locus of exceptionality: morpheme-specific phonology as constraint indexation. In L. Bateman, M. O'Keefe, E. Reilly, \& A. Werle (Eds.), University of Massachusetts occasional papers in linguistics 32: Papers in optimality theory III (pp. 259-296). Amherst: GLSA, University of Massachusetts.

Pierrehumbert, J., Beckman, M., \& Ladd, D. R. (2000). Conceptual foundations of phonology as a laboratory science. In N. Burton-Roberts, P. Carr, \& G. J. Docherty (Eds.), Phonological knowledge: conceptual and empirical issues (pp. 273-303). Oxford: Oxford University Press.

Plénat, M. (1996). De l'interaction des contraintes: une étude de cas. In J. Durand \& B. Laks (Eds.), Current trends in phonology: models and methods (Vol. 2, pp. 585-615). Salford: ESRI, University of Salford.

Prince, A., \& Smolensky, P. (1993/2004). Optimality theory: constraint interaction in generative grammar. Technical report, Rutgers University and University of Colorado at Boulder, 1993. Revised version published by Blackwell, 2004.

Roché, M., \& Plénat, M. (2003). Prosodic constraints on suffixation in French. In G. Booij, J. DeCesaris, A. Ralli, \& S. Scalise (Eds.), Topics in morphology. Selected papers from the third Mediterranean morphology meeting (Barcelona, September 20-22, 2001) (pp. 285-299). Barcelona: I.U.L.A., Universitat Pompeu Fabra.

Round, E. R. (forthcoming). Abstract architectural properties of the morphomic analysis of Kayardild. In M. Baerman, D. Brown, \& G. G. Corbett (Eds.), Understanding and measuring morphological complexity. Oxford: Oxford University Press. 978-0-19-872376-9.

Selkirk, E. (2012). The syntax-phonology interface. In J. Goldsmith, J. Riggle, \& A. Yu (Eds.), The handbook of phonological theory (2nd ed., pp. 435-484). Oxford: Blackwell.

Shannon, C. E. (1948). A mathematical theory of communication. The Bell System Technical Journal, 27, 379-423, 623-665.

Smith, J. C. (2013). The morphome as a gradient phenomenon: evidence from Romance. In S. Cruschina, M. Maiden, \& J. C. Smith (Eds.), The boundaries of pure morphology (pp. 247-261). Oxford: Oxford University Press.

Sproat, R., \& Fujimura, O. (1993). Allophonic variation in English /1/ and its implications for phonetic implementation. Journal of Phonetics, 21, 291-311.

Stump, G. (2001). Inflectional morphology: a theory of paradigm structure. Cambridge: Cambridge University Press. 